\title{
Policy-driven tobacco control
}

\author{
John A Francis, Erin M Abramsohn, Hye-Youn Park
}

California Department of Public Health, California Tobacco Control Program, Sacramento, California, USA

\section{Correspondence to} John A Francis, California Department of Public Health, California Tobacco Control Program, P0 Box 997377, MS 7206, Sacramento, California 95899-7377, USA; johnaveryfrancis@hotmail.com

Received 1 April 2009 Accepted 9 February 2010

\section{ABSTRACT}

Background Since the passage of Proposition 99, California's comprehensive tobacco control programme has benefited from a localised policy adoption process that allows for the innovation and diffusion of strong local tobacco control policies throughout the state.

Methods The policy adoption continuum is described in the context of California's smoke-free workplace movement, and the influence of policy-driven tobacco control initiatives on social norms, behaviour and the public's health was examined.

Results The Smoke-free California policy adoption continuum reflects a general approach for policy innovation and diffusion that builds social acceptance and influences social norms, while minimising unintended consequences and creating best practices in tobacco control. California's local smoke-free workplace policies have reduced secondhand smoke exposure and supported attitude and behaviour changes. The effects of local policy adoption led to the nation's first statewide smoke-free workplace law.

Conclusions Proposition 99 created an unprecedented tobacco control infrastructure that supported local policy innovation and diffusion to influence social norms and behaviours. Tobacco control policy efforts should address campaign challenges, oppose pre-emption and confront tobacco industry influence. Advocates must be cautious of pursuing a statewide policy prematurely, as it may result in a weak and/or pre-emptive policy that can stymie local policy efforts and prolong the adoption of a meaningful statewide policy.

\section{INTRODUCTION}

For over 20 years, California tobacco control advocates have employed voluntary and legislative policy processes as tools to yield long-term sustainable impacts on the health of their communities. Overall, tobacco control policies can be organised into three categories based on intent: (1) to educate individuals and influence health behaviours, (2) to create economic disincentives or (3) to regulate product production, distribution or use. ${ }^{12}$

\section{METHODS}

\section{Policy adoption continuum}

Proposition 99 and the creation of the California Tobacco Control Program (CTCP) generated a statewide infrastructure which laid the groundwork for a localised policy adoption process that in turn has allowed for the innovation, diffusion and refinement of tobacco control policies while minimising unintended consequences. ${ }^{34}$ Everett $\mathrm{M}$ Rogers defined diffusion of innovations as the process through which an innovation is communicated through certain channels over time among the members of a social system and categorises adopters of innovations into five categories: innovators, early adopters, early majority, late majority and laggards. ${ }^{5}$ The innovation and refinement of a given policy may occur across the following continuum of policy types, with varying impacts on social norms and the public's health.

\section{Voluntary policies}

Voluntary policies can be adopted by any individual or entity, and can be mandated only upon those persons who agree to be subject to the jurisdiction of the entity. ${ }^{6}$ Individuals, for example, can restrict smoking in their home, a business owner may voluntarily restrict smoking, and the owner of an apartment complex has the legal ability to voluntarily limit or prohibit smoking anywhere (including within units) on their property. ${ }^{7}$ However, voluntary policies are difficult to enforce, are generally limited in scope, are not easily tracked or measured, and do not typically have the force or effect of law. ${ }^{8}$ Despite these weaknesses, voluntary policies remain an important tool in circumstances where legislated policies are pre-empted by federal or state legislation or simply not politically feasible.

\section{Local resolutions and ordinances}

Local resolutions or ordinances may be established by any government or board authorised to set formal rules, such as a city, county, tribe, fair board, transit authority, or housing authority. ${ }^{6}$ A resolution reflects a formalised, written decision adopted by a governing body that encourages and promotes a particular action or a desired outcome. Like voluntary policies, resolutions are generally not enforceable and are limited in scope.

A local legislative ordinance is a law reflecting a mandate or directive that must be adhered to by those under the specific jurisdiction. Legislative policies are relatively easy to track and measure, and violations are typically subject to legal penalties such as fines, imprisonment, or court orders. Legislative policies are also subject to tobacco industry efforts to influence, weaken, or defeat policy adoption..$^{9-16}$ Given the tobacco industry's lack of credibility within many communities, their local efforts have generally been indirect and have focused on advocating for individual rights, disputing 'junk' science and providing erroneous calculations of economic impacts on local businesses. ${ }^{13} 1718$

\section{Policy strength and iteration}

The strength of a policy is dependent on a number of factors, including: restrictions, penalties, enforcement, implementation, public support, compliance and its lack of exemptions. A strong policy will include all of these factors and provide guidance regarding who may enforce the law and in what capacity. ${ }^{19}$ Compliance with a specific policy unlocked scheme, see http:// tobaccocontrol.bmi.com/site/ about/unlocked.xhtml 
will be dependent on knowledge, social acceptance and successful policy implementation.

Using Rogers' model, the innovation and diffusion of a specific policy across jurisdictions allows for refinement or modification of the policy. ${ }^{50}$ This becomes an iterative process that can help build social acceptance, identify policy gaps or loopholes and strengthen protections and enforceability. While few communities fall into the innovator or early adopter categories, the rate of diffusion (policy adoption) increases as jurisdictions become increasingly more confident to modify and adopt similar or stronger policies. ${ }^{21}$ Other factors influencing policy strength and innovation include community size and political environment, as well as social and geographical proximity to other communities with similar policies. ${ }^{20}$

\section{Statewide policies}

While the iterative process of policy adoption can occur at any level of government, the pursuit of a statewide policy should reflect best practices and establish meaningful standards that do not negate or limit future innovative local policy efforts. ${ }^{2}{ }^{3}$ At the state level there is greater likelihood for tobacco industry opposition, increased scepticism regarding a policy's legal and economic impact, and the potential for pre-emption (preemption is the process whereby a state legislature (or Congress) takes away the right of the lesser political subdivisions to enact laws in a certain policy area). ${ }^{132}$ Without strong public support for a policy, a weak and/or pre-emptive policy may lead to low compliance, have minimal impact on protections and behaviour, and may stifle local policy innovation.

This paper describes the policy adoption continuum in the context of California's smoke-free workplace movement, and examines the influence of policy-driven tobacco control initiatives on social norms, behaviour and public health. While 22 other states have adopted stronger statewide smoke-free policies, California's population size (37 million), diversity ( $56 \%$ nonwhite), geographic distribution (20\% rural), ${ }^{23}$ as well as the number of local jurisdictions (537), ${ }^{24}$ argues for engagement in strategic local tobacco policy work.

Moreover, California reflects the wide political diversity that can impact tobacco control policy efforts. For example, recent voting records from the 2006 ballot initiative to raise the state tax on cigarettes by $\$ 2.60$ per pack indicate support from $67 \%$ of San Francisco County voters compared to only $25 \%$ of Glenn County voters. ${ }^{25}$ Additionally, there are few states that have experienced the degree to which the tobacco industry has sought to influence local and state smoke-free legislation. ${ }^{13} 26$

\section{RESULTS}

\section{Smoke-free California: policies before Proposition $\mathbf{9 9}$}

The adoption of local (city or county) smoke-free workplace policies in California began in the 1970s, when local nonsmokers' rights groups ${ }^{13}$ began advocating for the specific designation of smoke-free enclosed spaces, including elevators, lobbies, conference rooms, public meetings and eventually public buildings. ${ }^{27}$ Initial smoke-free workplace policies followed the 1972 Surgeon General's Report that questioned the health risks of secondhand smoke exposure, but preceded the first significant study concerning secondhand smoke and lung cancer in 1981. ${ }^{28} 29$ Then, 5 years later, the 1986 Surgeon General's Report concluded that secondhand smoke caused disease among non-smokers. ${ }^{30}$

The strength of local smoke-free policies in California and the rate of diffusion of those policies reflected the growing scientific evidence concerning the effects of secondhand smoke exposure and the changes in public knowledge and attitudes towards smoking and secondhand smoke. While policies varied across jurisdictions, the protections generally strengthened over time. ${ }^{27}$

\section{California smoke-free workplaces}

By the time the CTCP began in 1989, over 250 workplace ordinances had already been adopted by California cities or counties. ${ }^{27}$ Concurrent with increases in programme funding and smoke-free policy initiatives, the tobacco industry presence in local California communities increased during the 1990s. From 1991 to 1992, tobacco industry spending to influence local policy efforts in California exceeded $\$ 2.4$ million. ${ }^{31}$ In response to negative public attitudes towards the tobacco industry, local industry efforts were coordinated primarily through smokers' rights groups, business organisations and eventually through public affairs groups and campaign firms. ${ }^{13} 15$

The tobacco industry often targeted high profile California communities and focused on discrediting the science, potential economic impacts, implementation costs and amendments in order to weaken policies. For example, in 1987 the tobacco industry heavily opposed the smoke-free ordinance in Beverly Hills by creating the Beverly Hills Restaurant Association. Using this association the industry was able to overturn the enacted ordinance 6 months after it was adopted. ${ }^{13}$ Nevertheless, during the early 1990s, local smoke-free workplace ordinances continued to proliferate and strengthen across the state.

In June 1990, Lodi, California became the first city in the US to pass an ordinance that incorporated 100\% smoke-free restaurants. And 2 months later, the City of San Louis Obispo, California, adopted the nation's first smoke-free bar law. ${ }^{28}$ As a result of local advocacy efforts and the coordination of a statewide campaign, the state of California had over 100 local smoke-free $(100 \%)$ restaurant policies by $1994 .^{28}$

\section{From local to statewide policy}

The first two attempts to adopt a statewide workplace policy occurred in the late 1970s, reflecting Berkeley, California's 1977 policy that created smoking and non-smoking restaurant sections. ${ }^{13}$ Following the adoption of hundreds of local smokefree workplace policies and the passage of Proposition 99, the tobacco industry recognised the value of a pre-emptive statewide policy that could overturn current local policies and curb the impact of strong local efforts. The first industry-supported bill, Senate Bill (SB) 376, failed in 1991 once the media revealed the extent of tobacco industry involvement. ${ }^{13}$

Assembly Bill (AB) 2667 proposed the first comprehensive smoke-free workplace law in 1992, but failed after multiple amendments that included pre-emptive language that would roll back many protections established by local governments. ${ }^{32}$ When the bill was reintroduced the following year as $A B 13$, it was met with mixed opinions from tobacco control advocates because the pre-emptive language had not been removed. $A B 13$ was also countered with an industry-supported bill ( $A B$ 996), that would have allowed smoking if basic ventilation standards were met. ${ }^{13} 32$ Over the 2-year legislative session, $A B 13$ underwent 11 amendments and numerous attempts by the tobacco industry to weaken the provisions and create exemptions.

The 1995 enacted version of AB 13 provided for 100\% smokefree workplaces and restaurants, but allowed for a number of exemptions, including a 2-year moratorium for bars and card rooms, which was later extended to 3 years. ${ }^{32}$ Additional confusion existed regarding the inclusion of pre-emptive language in the bill. Some perceived that the law pre-empted local governments from enforcing $A B 13$ and enacting stronger regulations, when in reality the pre-emptive language set 
a minimum standard of protection, allowing for the adoption and enforcement of stronger local smoke-free policies (so-called 'floor pre-emption'). ${ }^{33}$

The adoption of local smoke-free policies slowed considerably following the passage of $\mathrm{AB} 13$ (figure 1). Although some attributed this to a chilling effect caused by the new law, ${ }^{22}$ it was more likely due to a programmatic shift of state and local tobacco control efforts to protect $A B 13$ and facilitate local implementation. Future innovation of local smoke-free policies focused on eliminating the exemptions in $\mathrm{AB} 13$ and creating smoke-free outdoor spaces. ${ }^{27}$

\section{DISCUSSION}

California's smoke-free movement provides a context to examine the progression and influence of tobacco-related policy efforts. For the purposes of interpretation, the discussion is organised by the following four concepts: (1) policy-driven tobacco control, (2) social norm change, (3) atypical policies, and (4) emerging smoke-free outdoor policies.

\section{Policy-driven tobacco control}

CTCP funds local programmes to work on changing the environments in which people begin smoking and are able to quit, with the goal of 'denormalising' tobacco use. This work takes place at the community level within four priority areas: (1) eliminating secondhand smoke exposure, (2) revealing and countering tobacco industry influence, (3) reducing access to tobacco products and (4) providing cessation services. ${ }^{34}$ The social norm change paradigm demonstrates that long-term change will occur through the adoption and implementation of policies. A change in social norm typically begins with public apathy and requires an increase in public awareness in order to achieve the social concern necessary to address the problem. ${ }^{3} 34$ A strong policy should be sustainable, requiring little maintenance following implementation, allowing programmes to pursue future tobacco-related policies.

Policy strength should also be considered as a policy is refined and advanced from the local to state level. When reviewing the provisions and exemptions in local policies adopted prior to 1994, it is likely that a state law adopted in California prior to 1994 would have included greater exemptions (eg, bars) and/or pre-emption. Conversely, had more time been allowed to strengthen local policies and further increase the demand for

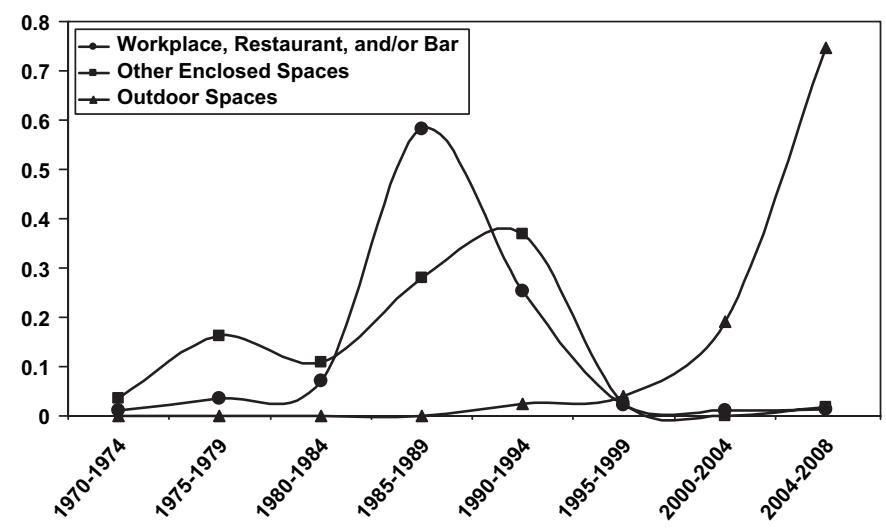

Figure 1 Proportion of local smoke-free ordinances by time period. Sources: Americans for Nonsmokers' Rights Local Tobacco Control Ordinance Database, 1970-2008; California's Clean Air Project Secondhand Smoke Policy Database, 2004-2008; The Center for Tobacco Policy and Organizing, 2004-2008. smoke-free spaces, California may have passed a stronger statewide policy with fewer exemptions.

Over the 20 years following the passage of Proposition 99, 22 other states had adopted stronger comprehensive statewide policies without first adopting as many local policies as in California $^{35}$; however, the experience of local refinement and diffusion in California has informed the policy process in other states, and reflects the strengthened evidence regarding the health effects of secondhand smoke exposure. Following the 2006 Surgeon General's report concluding that there is no safe level of exposure, ${ }^{36}$ the largest roadblock for states continues to be weak and pre-emptive statewide laws.

The strength and impact of a policy may also be minimised if the intent of the policy is unclear or influenced by competing interests. This may in turn prevent the adoption of future policies. ${ }^{12}$ For example, due to exemptions in California's statewide smoke-free workplace policy, California is precluded from acknowledgement as a smoke-free state by the Centers for Disease Control and Prevention. ${ }^{35}$ Recent attempts to remove the exemptions in the statewide law have failed. In the 2007 veto message for $A B$ 1467, the Governor disagreed with placing further restrictions on businesses and suggested increasing access to cessation services offered through the highly effective California Smokers' Helpline' as an alternate strategy. ${ }^{37}$

\section{Social norm change}

In the social norm change paradigm, tobacco control policy is viewed as a measurable, short-term outcome. ${ }^{39}$ Whether policies address the price of tobacco, secondhand smoke exposure, access to tobacco, or countering the tobacco industry, the result of successful policy implementation eventually leads to intermediate outcomes, such as compliance with the policy, decreased consumption and increased quit attempts. ${ }^{38}$

In the case of smoke-free workplace policies, the refinement and diffusion of policies has helped influence reductions in involuntary secondhand smoke exposure. Figure 2 shows the cumulative number of local smoke-free policies with the reported percentage of smoke-free workplaces and non-exposure in California. From 1990 to 2005, 2-week workplace exposure rates dropped from $29 \%$ to $14 \%$. By 2005 , 95\% of Californians reported having a smoke-free indoor workplace. During the same period, cigarette consumption among daily smokers declined $20 \%$ from 17.3 to 13.8 cigarettes per day, while a greater number of smokers reported considering and making quit attempts. ${ }^{39}$ Since the start of the CTCP, overall cigarette consumption in California has declined by $60.8 \%{ }^{40}$

The diffusion of smoke-free policies was also associated with changes in individual knowledge, attitudes and behaviours. In addition to the increased proportion of smoke-free workplaces, support for smoke-free restaurants grew among California smokers and non-smokers (figure 3). Further, between 1996 and 2005, the number of adults reporting a smoke-free home increased from $64 \%$ to $83 \%$ (figure 2).

\section{Atypical policies}

Tobacco control policies have been adopted successfully at the state level without first being pursued locally. In California this typically occurs when a policy is only feasible through legislative action, or when a policy is only relevant to a particular level of government. For example, on January 1, 2008, California became the third state in the country (following Arkansas and Louisiana) to enact a smoke-free car law. Following four previous attempts in the California State Legislature, a bill was reintroduced to restrict smoking in cars where minors (under 18) are 


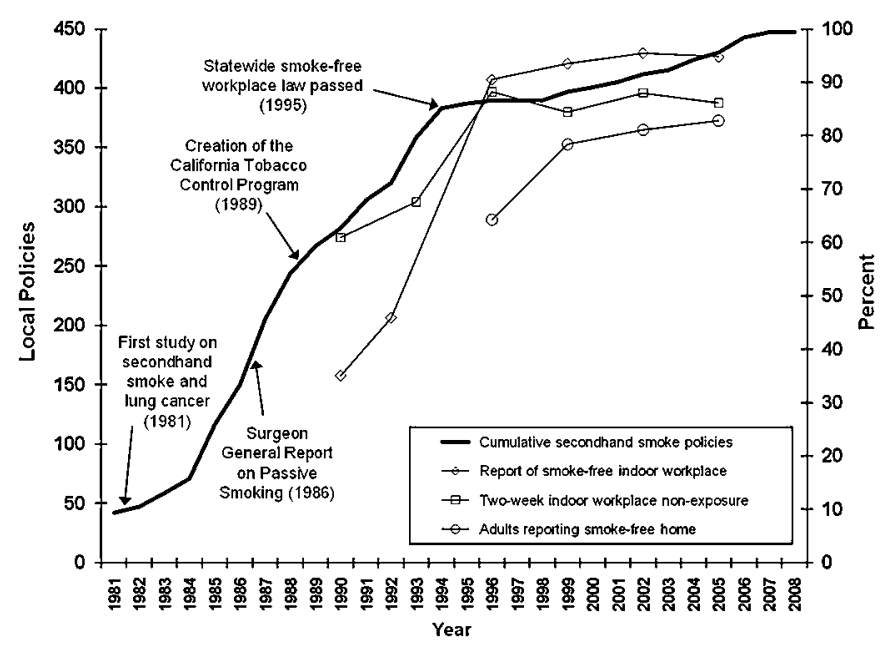

Figure 2 Cumulative local secondhand smoke. Policies and secondhand smoke reporting. Sources: California adult tobacco survey and California Tobacco Survey; Americans for Nonsmokers' Rights Local Tobacco Control Ordinance Database, 1970-2008.

present. $^{32}$ While the intent of this policy was to reduce involuntary secondhand smoke exposure, the regulation of smoking in cars at the local level was unrealistic and would likely have been unenforceable.

\section{Emerging smoke-free policies in California}

Today, smoke-free policy innovation and diffusion is occurring at the voluntary, local and state level. Given the knowledge and social demand for smoke-free spaces, local jurisdictions have begun to adopt smoke-free policies aimed at reducing secondhand smoke exposure in outdoor public spaces and multi-unit housing complexes.

\section{Comprehensive smoke-free outdoor policies}

In outdoor settings secondhand smoke can present a nuisance and a significant health hazard, ${ }^{41}$ with specific locations, such as entryways, outdoor dining areas and bus shelters having a greater risk for involuntary exposure. In response, several municipalities have found the health risks compelling enough to adopt a comprehensive outdoor policy. Currently, a comprehensive outdoor smoke-free policy is defined as one that prohibits smoking in at least five of the seven major outdoor areas: outdoor dining areas, entryways, public events, recreation areas, service areas, sidewalks and worksites. ${ }^{42}$

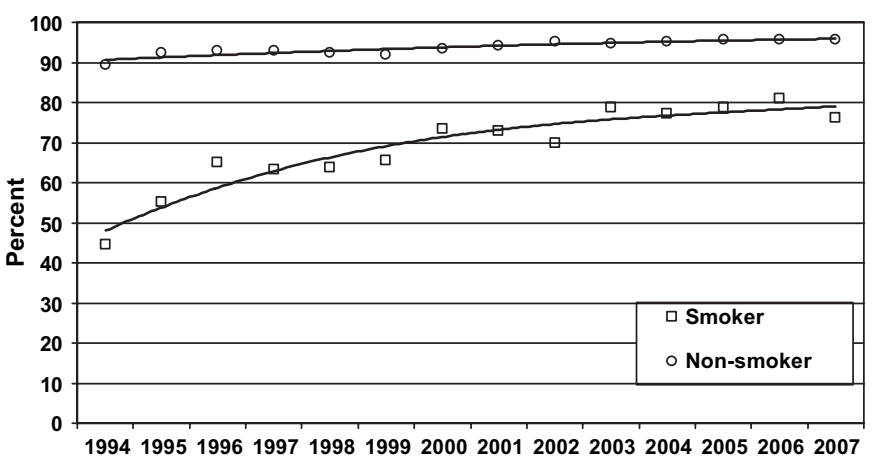

Figure 3 Percentage of California smokers and non-smokers that prefer smoke-free restaurants, 1994-2007. Source: California adult tobacco survey, 1994-2007. Prepared by California Department of Public Health, California Tobacco Control Program, 2009.
Following the 2006 California Air Resources Board (ARB) classification of secondhand smoke as a toxic air contaminant, ${ }^{43} 44$ Calabasas, CA became the first city to adopt and implement a comprehensive outdoor smoke-free policy. By the end of 2008, 20 California cities and counties had adopted comprehensive outdoor policies. $^{42}$

\section{Multi-unit housing}

Local advocates are also working to increase the number of voluntary and legislative policies that provide smoke-free living spaces. While this work is moving towards protections in private spaces, it is completely legal to restrict smoking in multi-unit housing units or buildings. ${ }^{7}$ Voluntary and local legislative policies are able to restrict smoking in residential units, on patios/balconies, and in indoor and outdoor common areas. Legislative policies may also limit or restrict grandfathering provisions, classify secondhand smoke as a nuisance and require disclosure of smoking policies to prospective tenants or buyers. By October 2008, 22 California cities had adopted local multiunit housing ordinances with cities such as Temecula, Belmont, Calabasas, Novato and Loma Linda including provisions that require the creation of smoke-free units. ${ }^{45}$

In 2008, SB 1598 was introduced to authorise landlords to prohibit smoking in residential units. ${ }^{32}$ The intent of the bill was to provide landlords with additional legal protections and encourage the adoption of local voluntary policies. The bill proposed a grandfathering provision, however, which would have significantly limited the adoption and implementation of future local voluntary policies. Following a number of amendments and opposition by major voluntary health organisations, the bill was removed from consideration. ${ }^{32}$

As California's policy adoption efforts to protect non-smokers in multiunit housing evolve, public health officials and advocates continue to focus on increasing public knowledge and acceptance of multi-unit housing policies and increasing the number and quality of protections provided at the local level. Future statewide laws should establish a minimum level of protection without pre-empting local jurisdictions from adopting stronger tobacco control policies that reduce secondhand smoke exposure in multi-unit housing complexes.

\section{Conclusions}

Proposition 99 created an unprecedented tobacco control infrastructure in California and provided funding for local advocacy programmes throughout the state. The programme's success is due in part to the state's ability to promulgate a strategic vision, provide training and maintain a local tobacco control infrastructure that requires accountability on the part of local health agencies and non-governmental organisations to focus on policydriven tobacco control efforts. ${ }^{34}$

Local policy-driven campaigns have the ability to innovate and diffuse policies that support comprehensive state-level tobacco control efforts to change social norms and achieve the goal of reducing tobacco-related disease and death. Refining policies at the local level helps identify gaps in policies, minimise negative outcomes and build social acceptance. These efforts can contribute to achievement of strong, non-pre-emptive state-level policies that allow for continued local innovation and diffusion. Pursuing a state policy prematurely may result in a weak and pre-emptive policy that can stymie local policy efforts and prolong the adoption of a meaningful statewide policy.

At any given time, the number, type and strength of tobaccorelated policies will vary across jurisdictions and among states. While multiple policies can be pursued simultaneously along the 


\section{What this paper adds}

- The policy adoption continuum is presented in the context of California's smoke-free workplace movement, and examines the influence of policy-driven tobacco control initiatives on social norms, behaviour and the public's health.

- This paper addresses the inherent challenges associated with the innovation and diffusion of strong tobacco control policies and addresses tobacco industry tactics, pre-emption, misconceptions and the dangers of passing statewide policies prematurely.

- Given the increased knowledge and social demand for smokefree spaces, the authors discuss emerging policies aimed at reducing secondhand smoke exposure in outdoor public spaces and multiunit housing complexes.

continuum, state and local programmes must coordinate and prioritise their efforts to maximise limited resources and maintain focus. Tobacco control programmes and advocates should proactively address the challenges to adopting and implementing policies, oppose pre-emption and confront tobacco industry influence by exposing historical and current tobacco industry practices to influence the policy process. ${ }^{46-48}$

Competing interests None.

Provenance and peer review Not commissioned; not externally peer reviewed.

\section{REFERENCES}

1. Aquilino ML, Lowe JB. Approaches to tobacco control: the evidence base. Eur J Dent Educ 2004;8(Suppl 4):11-17.

2. Isaacs SL, Knickman JR Series Editor. A Pathway to "Tobacco Control Policy": Robert Wood Johnson Foundation Series on Health Policy, 2006.

3. California Department of Health Services, Tobacco control section. A model for change: the california experience in tobacco control. Sacramento, CA: California Department of Health Services, 1998.

4. Cummings KM. Community-wide interventions for tobacco control. Nicotine Tob Res 1999;1(Suppl 1):S113-16.

5. Rogers EM. Diffusion of Innovations. 5th edn. New York, NY: Free Press, 2003

6. Communities of Excellence In Tobacco Control, Module 2: conducting a communities of excellence needs assessment, 2006. http://www.cdph.ca.gov/ programs/tobacco/Documents/CTCPCX2006-Module2.pdf.

7. Public Health Institute. How landlords can prohibit smoking in rental housing. Technical Assistance Legal Center, 2006 (revised June 2008).

8. Colgan SE, Skinner B, Mage C, et al. Business policies affecting secondhand smoke exposure. N C Med J 2008;69:355-61.

9. Nixon ML, Mahmoud L, Glantz SA. Tobacco industry litigation to deter local public health ordinances: the industry usually loses in court. Tob Control 2004; 13:65-73.

10. Givel MS, Glantz SA. Tobacco lobby political influence on US state legislatures in the 1990s. Tob Control 2001:10:124-34.

11. Bal DG. Designing an effective statewide tobacco control program-California. Cancer 1998;83(12 Suppl):2717-21.

12. Henson R, Medina L, St Clair S, et al. Clean indoor air: where, why, and how. J Law Med Ethics 2002;30(3 Suppl):75-82.

13. Glantz SA, Balbach ED. Tobacco war: inside the California battles. Berkeley, California: University of California Press, 2000.

14. Tesler LE, Malone RE. Corporate philanthropy, lobbying, and public health policy. Am J Public Health 2008;98:2123-33.

15. Traynor MP, Begay ME, Glantz SA. New tobacco industry strategy to prevent local tobacco control. JAMA 1993;270:479-86.

16. Novotny TE, Siegel MB. California's tobacco control saga. Health Aff (Millwood) 1996;15:58-72.

17. Magzamen S, Charlesworth A, Glantz SA. Print media coverage of California's smokefree bar law. Tob Control 2001;10:154-60.

18. Ong EK, Glantz SA. Constructing "sound science" and "good epidemiology": tobacco, lawyers, and public relations firms. Am J Public Health 2001;91:1749-57.

19. Chriqui JF, Frosh M, Brownson RC, et al. Application of a rating system to state clean indoor air laws (USA). Tob Control 2002;11:26-34.

20. Rogers EM, Peterson JC. Diffusion of clean indoor air ordinances in the southwestern United States. Health Educ Behav 2008;35:683-97.
21. Nykiforuk CI, Eyles J, Campbell HS. Smoke-free spaces over time: a policy diffusion study of bylaw development in Alberta and Ontario, Canada. Health Soc Care Community 2008;16:64-74.

22. Macdonald HR, Glantz SA. Political realities of statewide smoking legislation: the passage of California's Assembly Bill 13. Tob Control 1997;6:41-54.

23. U.S. Census Bureau. American community survey, 2006-2008. http://www. census.gov/acs/www/ (accessed 20 Oct 2009).

24. California Department of Finance. Population estimates for cities, counties, and the state. http://www.dof.ca.gov/research/demographic/reports/estimates/e-1/ 2008-09/ 2008-2009 (accessed 20 Oct 2009).

25. California Secretary of State. Statement of Vote, November, 2006 General Election - State Ballot Measures, 2006. http://www.sos.ca.gov/elections/sov/ 2006_general/measures.pdf (accessed 0ct 2009)

26. Morley CP, Cummings KM, Hyland A, et al. Tobacco Institute lobbying at the state and local levels of government in the 1990s. Tob Control 2002:11(Suppl 1):I102-9.

27. Americans for Nonsmokers' Rights Foundation. American Nonsmokers' Rights Foundation Local Tobacco Control Ordinance Database. Berkeley, CA: Am. Nonsmokers' Rights Found, 2008.

28. U.S. Department of Health and Human Services. The health consequences of smoking: a report of the surgeon general. Washington: U.S. Department of Health, Education, and Welfare, 1972.

29. Hirayama T. Non-smoking wives of heavy smokers have a higher risk of lung cancer: a study from Japan. Br Med J (Clin Res Ed) 1981:282:183-5.

30. U.S. Department of Health and Human Services. The health consequences of involuntary smoking: a report of the surgeon general. Rockville, MD: U.S. Department of Health and Human Services, Centers for Disease Control and Prevention, National Center for Chronic Disease Prevention and Health Promotion, Office on Smoking and Health, 1986.

31. Begay ME, Traynor M, Glantz SA. The tobacco industry, state politics, and tobacco education in California. Am J Public Health 1993;83:1214-21.

32. Legislative Counsel of California. California legislative information. http://www. leginfo.ca.gov/ (accessed 09/2008)

33. Mermin SE, Graff SK. A legal primer for the obesity prevention movement. Am J Public Health 2009:99:1799-805.

34. Roeseler A, Feighery E, Cruz TB. Tobacco marketing in California and implications for the future. Tob Control 19(Supp 1):21-30.

35. State smoking restrictions for private-sector worksites. Restaurants, and bars-United States, 2004 and 2007. MMWR Morb Mortal Wkly Rep 2008;57:549-52. http://www.cdc.gov/mmwr/preview/mmwrhtml/mm5720a3.htm.

36. U.S. Department of Health and Human Services. The health consequences of involuntary exposure to tobacco smoke: a report of the surgeon general. Rockville, MD: U.S. Department of Health and Human Services, Centers for Disease Control and Prevention, Coordinating Center for Health Promotion, National Center for Chronic Disease Prevention and Health Promotion, Office on Smoking and Health, 2006. http://www.surgeongeneral.gov/library/secondhandsmoke/report/.

37. Anon. Governor veto message 10/14/2007. http://www.leginfo.ca.gov/pub/07-08/ bill/asm/ab_1451-1500/ab_1467_vt_20071014.html (accessed 16 Dec 2008).

38. California Department of Health Services, Tobacco Control Section. California tobacco control update 2006: the social norm change approach, Sacramento, CA: California Department of Health Services, Tobacco Control Section, 2006.

39. Al-Delaimy WK, White MM, Trinidad DR, et al. The California tobacco control program: can we maintain the progress? results from the California tobacco survey, 1990-2005. Sacramento, CA: California Department of Public Health, 2008.

40. Tobacco Education and Research Oversight Committee. Endangered investment: toward a tobacco-free California 2009-2011-Master Plan. Sacramento, CA: Tobacco Education and Research Oversight Committee, 2009.

41. Klepeis NE, Ott WR, Switzer P. Real-time measurement of outdoor tobacco smoke particles. J Air Waste Manage Assoc 2007;57:522-34.

42. The Center for Tobacco Policy and Organizing. Comprehensive outdoor secondhand smoke ordinances. American Lung Association of California, Aug 2008. http://www.center4tobaccopolicy.org/ files/ files/COMPREHENSIVE\% 20SMOKEFREE\%200UTDOOR\%20AREA\%200-RDINANCES August2008(1).pdf.

43. State of California, Air Resources Board. Press Release: California Identifies Secondhand Smoke as a "Toxic Air Contaminant" 2006.

44. State of California Air Resources Board. Proposed identification of environmenta tobacco smoke as a toxic air contaminant. In: California Environmental Protection Agency, ed. 2005. ftp://ftp.arb.ca.gov/carbis/regact/ets2006/app3part\%20a.pdf

45. Center for Tobacco Policy and Organizing. Policy and organizing matrix of loca smoke-free housing policies, Oct 2008. http://www.center4tobaccopolicy.org/ files/ files/Matrix\%20of\%20Local\%20Smokefree\%20Housing\%20Policies\%200ctober\% 202008.pdf.

46. Hersey JC, Niederdeppe J, Ng SW, et al. How state counter-industry campaigns help prime perceptions of tobacco industry practices to promote reductions in youth smoking. Tob Control 2005;14:377-83.

47. The Center for Tobacco Policy and Organizing. Tobacco Money in California Politics. Campaign Contributions and Lobbying Expenditures of Tobacco Interests: Report for the 2005-2006 Election Cycle: The American Lung Association of California, 2007. http://www.center4tobaccopolicy.org/ files/ files/5192 Tobacco\% 20Money\%20in\%20California\%20Politics\%20Report\%20for\%20̄the\%202005-2006\% 20Election\%20Cycle.pdf.

48. The Center for Tobacco Policy and Organizing. Tobacco Money \& Politics Sacramento, CA: The American Lung Association of California, 2008. http://www. center4tobaccopolicy.org/tobaccomoney. 